\title{
Numerical Investigation of the Effects of Leakage Flow From Guide Vanes of Francis Turbines using Alternative Clearance Gap Method
}

\author{
S. Gautam ${ }^{1,2}$, H. P. Neopane ${ }^{1}$, B. S. Thapa ${ }^{1}$, S. Chitrakar ${ }^{1}$ and B. Zhu ${ }^{2 \dagger}$ \\ ${ }^{1}$ Turbine Testing Lab, Kathmandu University, Dhulikhel, 45210, Nepal \\ ${ }^{2}$ Department of Energy and Power Engineering, Tsinghua University, Beijing, 10084, China \\ †Corresponding Author Email: bszhu@mail.tsinghua.edu.cn
}

(Received July 23, 2019; accepted February 3, 2020)

\begin{abstract}
Flow around the Guide vanes (GV) in Francis turbine differs with the shape of hydrofoils. The difference in the pressure of fluid travelling to pressure side and suction side of GV contributes to flow behavior. This study presents the numerical technique using alternative clearance gap method to predict the flow around GV and its consequent effect on turbine performance. GV profile has a significant effect on the performance of the turbine with sediment contained fluid flow. In this paper, symmetrical NACA 0012 and cambered NACA 2412, NACA 4412 hydrofoils are studied introducing $0 \mathrm{~mm}, 2 \mathrm{~mm}$, and $4 \mathrm{~mm}$ clearance gaps. Vortex filament can be seen when fluid leaves the clearance gap due to the leakage flow occurring through the gap. The intensity of vortex leaving clearance gap rises with an increase in the size of the clearance gap. However, in the case of asymmetrical GV profile, the velocity of fluid travelling along the vortex compared to that of symmetrical hydrofoil is lower. In case of low specific speed Francis turbines, this vortex is found to be a major reason to erode the runner surface due to high velocity of a sand particle travelling with them. With the alternative clearance gap approach, this paper compares the pressure pulsation downstream of GVs contributed by leakage flow for three NACA profiles, whose frequency is half of blade passing frequency.
\end{abstract}

Keywords: Francis turbine; Sediment erosion; Leakage flow; Vortex; Efficiency; RSI; Blade passing frequency.

\section{NOMENCLATURE}

$\begin{array}{ll}\text { CTP } & \text { Normalized Total Pressure } \\ E & \text { specific hydraulic energy of turbine } \\ e_{a} & \text { approximate relative error } \\ e_{e x t} & \text { extrapolated relative error } \\ f & \text { frequency } \\ f_{b} & \text { blade passing frequency } \\ \text { GCI Iine }^{*} & \text { Grid Convergence Index of fine mesh } \\ n^{*} & \text { dimensionless runner rotation } \\ h & \text { size of grid } \\ \text { RSI } & \text { Rotor Stator Interaction }\end{array}$

\section{INTRODUCTION}

Hydro-turbines experiences severe effects while operated with sediment driven water flowing from Himalaya basins of South Asia (Thapa, 2004; Thapa, Dahlhaug, and Thapa, 2012). Francis turbines are reaction type machines which are severely affected due to sediment content in water (Neopane, Dalhaug, and Cervantes, 2012). However, the need and

$\begin{array}{ll}P & \text { pressure } \\ P^{*} & \text { dimensionless pressure } \\ \bar{P} & \text { average pressure } \\ \text { PS } & \text { Pressure Side } \\ R & \text { grid refinement factor } \\ \text { SS } & \text { Suction Side } \\ & \\ \phi & \text { variable for GCI calculation } \\ \rho & \text { density }\end{array}$

prospects of Francis type machine around the globe are reported to be around $80 \%$ (Lama et al, 2018). The assembly of Francis turbine consists of a spiral casing, stay vanes, guide vanes, runner and a draft tube.

Guide vanes (GVs) are the important part of Francis turbine assembly that contributes to the conversion of total available hydraulic energy partly into acceleration energy. Flow while entering the GV 
experiences accelerated flow. These high velocities of the fluid flow leaving GV enters runner at a designed angle. This imparts rotational kinetic energy to runner blades and leave the runner domain from the draft tube. However, to make it capable of entering fluid to the desired amount during different load variations, GV can freely rotate from its axis. This allowance for GV rotation is possible due to the clearance gap in between GV surface and the facing plate. During no operation of the Francis turbine, the available gap between GV surface and facing plate is minimum, called as Dry Clearance. However, the size of clearance gap increases due to hydrostatic pressure between $\mathrm{GV}$ and facing plates.

Apart from the hydrostatic pressure, the size of the gap also increases due to shear forces from particles contained in the fluid. These sediment particles can enter the clearance gap of GVs. Gradually, these particles shear off the walls of GV surface towards facing plate (Thapa, Dahlhaug, and Thapa, 2015). The behavior of fluid flow from GV is highly unpredictable, due to wakes through trailing edge and cross leakage flow through the clearance gap (Eide and Brekke, 2002, Eide, 2004, Brekke, 1988). Experimental investigations on flow behavior in GV were carried out in past to predict the effect of outflow from GV trailing edge towards runner inlet (Thapa, Dahlhaug, and Thapa, 2018; Chitrakar, Thapa, Neopane and Dahlhaug 2017, Chitrakar, Thapa, Dahlhaug and Neopane, 2017). This results in the highest wear in the $\mathrm{GV}$ region due to accelerated flow through GV surface and leakage flow (Koirala, Thapa, Neopane, and Zhu, 2016). The consequences resulted in the formation of vortex flow in guide vanes, thus accelerating the sediment erosion (Chitrakar, Neopane and Dahlhaug, 2016).

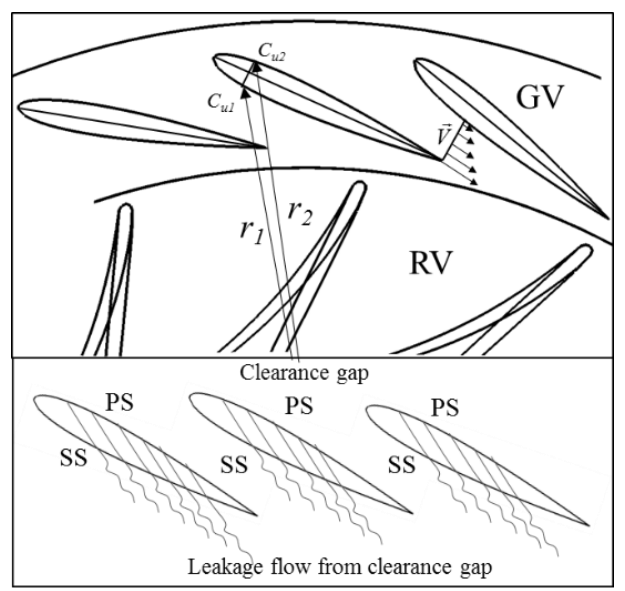

Fig. 1. Leakage flow due to pressure difference.

When water flows through GV leading edge, flow is divided into two adjacent GV surfaces. One surface is located at a higher radius from center of the turbine and the other is located to the smaller radius as shown in Fig. 1. This difference in radius of fluid flowing domain differentiates these sides to be: i) Pressure Side (PS) where the radius is larger and ii) Suction Side (SS) to smaller radius side. Hence pressure difference is created in between these sides which tend to pull water towards the suction side. This will result to the cross-leakage flow from the clearance gap (Koirala, Zhu and Neopane, 2016). The amplification of non-uniform velocity profile after water leaves stay vanes gets cumulated with leakage flow from $\mathrm{GV}$ surface, resulting in more irregularities. The erosion in the suction side of GV is predominant due to heavy vortex flow. However, local separation and turbulence created results wear in all sides of the GV (Brekke, 1988).

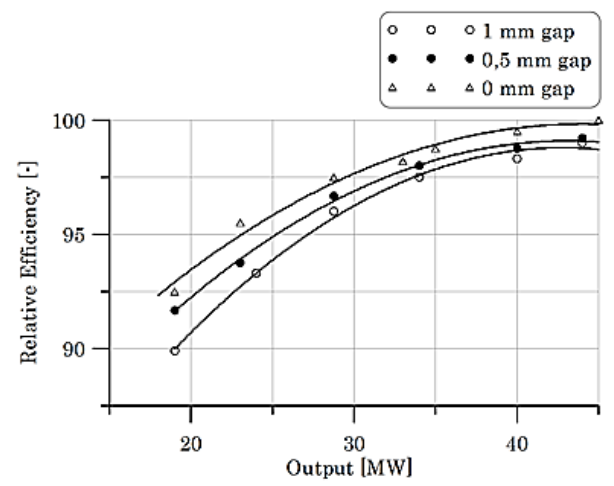

Fig. 2. Effect of leakage flow in the efficiency of turbine (Brekke, 1988).

The increase in the size of clearance gap due to erosive wear reduces the overall efficiency of the turbine (Koirala, Zhu and Neopane, 2016; Koirala, Thapa, Neopane, Zhu and Chhetry, 2016). Figure 2 shows the efficiency measurement of Francis turbine with different size of clearance gaps. The efficiency of the turbine decreased by about $2.5 \%$ with the increase in the size of clearance up to $1 \mathrm{~mm}$ (Brekke, 1988). This can be severe in the context of hydropower plant operating with very high sediment concentration in Nepal. It was reported that size of clearance gap was around $10 \mathrm{~mm}$ at some locations of Kaligandaki 'A' hydropower plant Nepal, due to sediment erosion (Koirala, Thapa, Neopane, Zhu and Chhetry, 2016). In a similar study, erosion depth up to $35 \mathrm{~mm}$ at some locations of $\mathrm{GV}$ of Bhilangana HPP, India was observed (Acharya et al, 2019, Gautam et al, 2020).

This study uses an alternative clearance gap method to distinguish the effect of leakage flow with the rotor-stator interaction to compare GVs with different profiles. In presented study NACA 0012, NACA 2412 and NACA 4412 hydrofoil is used. NACA 0012 is symmetric hydrofoil with maximum thickness $12 \%$ of total chord length at $30 \%$ of chord. Hydrofoils NACA 2412 and NACA 4412 are asymmetrical hydrofoils with camber of $2 \%$ and $4 \%$ respectively at $40 \%$ chord as shown in Fig. 3. By using Fast Fourier Transform (FFT) of the signals, resulting amplitudes of harmonics at blade passing frequency is differentiated from the amplitudes contributed by leakage flow (Gautam et al, 2019). This study compares the resulting amplitudes of pressure pulsations due to leakage flow for symmetrical and asymmetrical GV profiles. 


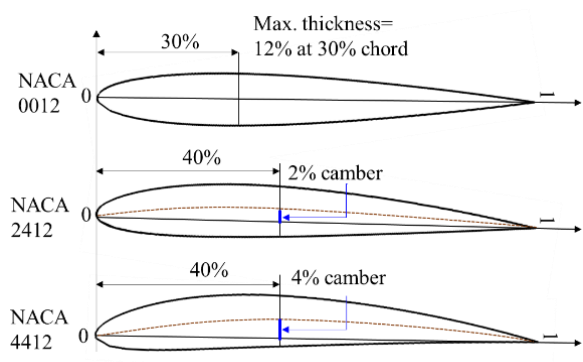

Fig. 3. Geometry of different GV profiles.

\section{NUMERICAL MODEL}

\subsection{Boundary Conditions}

This study uses a prototype turbine of Jhimruk Hydropower Plant, 12.3 MW. Figure 4 shows the numerical model of the current study. The geometry of the turbine runner was designed with the site specification of a power plant using in house turbine design software 'Khoj'. Curves from Khoj were imported to ICEM CFD 17.1 to generate the required fluid flow domain. There are $24 \mathrm{GVs}$ in the prototype turbine. The numerical model of the current case uses $24 \mathrm{GVs}$ with 12 clearance gaps alternatively as shown in Fig. 4. Structured mesh for the fluid flowing domain was created in ICEM CFD. Mesh were refined near a wall to capture the wakes leaving a trailing edge. Mesh for each GV, clearance gap and runner were created separately. Mesh for each domain was connected in the numerical model using a suitable interface during steady and transient state numerical analysis. In this case, the rotational speed of the runner was provided as $1000 \mathrm{rpm}$, which corresponds to the speed of the actual turbine. At the inlet of model, mass flow rate of $2350 \mathrm{~kg} / \mathrm{s}$ with cylindrical velocity component of $(0,-0.34,-0.94)$ from actual case of power plant was given and at the outlet average static pressure of 1 atmospheric pressure was set, which is widely accepted boundary condition for numerical simulation of hydraulic turbines (IEC, 1991). GV blades, runner blades, hub and shroud were specified walls with no-slip condition. At the inlet of the domain, 5\% turbulence intensity was used.

\subsection{Governing Equations and Turbulence Model}

The commercial CFD solver ANSYS-17.1 was used for numerical simulations in steady-state and transient conditions using high-resolution discretization in advection scheme. Transient Blade Row model was used for unsteady analysis. The solution of $0.06 \mathrm{~s}$ time, equivalent to 1 revolution of the runner was recorded after the solution was converged. The convergence criteria for mass, momentum and turbulence parameters were set to a root-mean-square (RMS) value $1 \mathrm{E}-4$. The inner loop iteration for transients at each time step was selected to be 10 .

Reynolds averaged Navier-Stokes (RANS) was used to solve the numerical model for incompressible flow. For an incompressible and isothermal fluid, equation of continuity and momentum are written in the form of Navier-Stokes equation in $\mathrm{x}$-direction as,

$$
\begin{aligned}
& \rho\left[\frac{\partial u}{\partial t}+\frac{\partial}{\partial x}\left(u^{2}\right)+\frac{\partial}{\partial y}(u v)+\frac{\partial}{\partial z}(u w)\right]= \\
& -\frac{\partial p}{\partial x}+\mu\left[\frac{\partial^{2} u}{\partial x^{2}}+\frac{\partial^{2} u}{\partial y^{2}}+\frac{\partial^{2} u}{\partial z^{2}}\right]
\end{aligned}
$$

The time-averaged Navier-Stokes equations can be brought together as in the form of RANS equation,

$$
\begin{aligned}
& \rho\left[\frac{\partial}{\partial x}\left(\bar{u}^{2}\right)+\frac{\partial}{\partial y}(\overline{u v})+\frac{\partial}{\partial z}(\overline{u w})\right]=-\frac{\partial \bar{p}}{\partial x}+ \\
& \mu\left[\frac{\partial^{2} \bar{u}}{\partial x^{2}}+\frac{\partial^{2} \bar{u}}{\partial y^{2}}+\frac{\partial^{2} \bar{u}}{\partial z^{2}}\right]- \\
& {\left[\frac{\partial}{\partial x}\left(\rho \overline{u^{\prime 2}}\right)+\frac{\partial}{\partial y}\left(\rho \overline{u^{\prime} v^{\prime}}\right)+\frac{\partial}{\partial z}\left(\rho \overline{u^{\prime} w^{\prime}}\right)\right]}
\end{aligned}
$$

This study uses the Shear Stress Transport (SST) turbulence model for its good behavior in adverse pressure gradients and separating flow. The equations are defined as,

$$
\begin{aligned}
& \frac{\partial(\rho k)}{\partial t}+\frac{\partial\left(\rho u_{j} k\right)}{\partial x_{j}}=p-\beta^{*} \rho \omega k+ \\
& \frac{\partial}{\partial x_{j}}\left[\left(\left(\mu+\sigma_{k} \mu_{t}\right) \frac{\partial k}{\partial x_{j}}\right)\right] \\
& \frac{\partial(\rho \omega)}{\partial t}+\frac{\partial\left(\rho u_{j} \omega\right)}{\partial x_{j}}=\frac{\gamma}{v_{t}} p-\beta \rho \omega^{2}+ \\
& \frac{\partial}{\partial x_{j}}\left[\left(\left(\mu+\sigma_{\omega} \mu_{t}\right) \frac{\partial \omega}{\partial x_{j}}\right)\right]+ \\
& 2\left(1-F_{1}\right) \frac{\rho \sigma_{\omega 2}}{\omega} \frac{\partial k}{\partial x_{j}} \frac{\partial \omega}{\partial x_{j}}
\end{aligned}
$$

This equation gives good agreement between masstransfer simulations with experimental data (Chitrakar, Thapa, Dahlhaug, and Neopane, 2017). The sensitivity study of the turbulence models SST, BSL and Omega RS suggests SST model be suitable for the current case too (Chitrakar, Thapa, Dahlhaug, and Neopane, 2016).

\section{VAlidation OF The Reference CASE}

\subsection{Mesh Sensitivity Analysis}

This study uses GCI technique to estimate the discretization error (Celik et al, 2008). Three different mesh was created as Coarse, Medium and Fine. The number of elements at each edge in a 3-D surrounding block of geometry were increased by $1.5 \mathrm{x}$. For the uncertainty measurement clearance gaps were not introduced. Discretization error for the numerical was determined as follows:

i) The average length of each element for a 3-D mesh was determined as, 


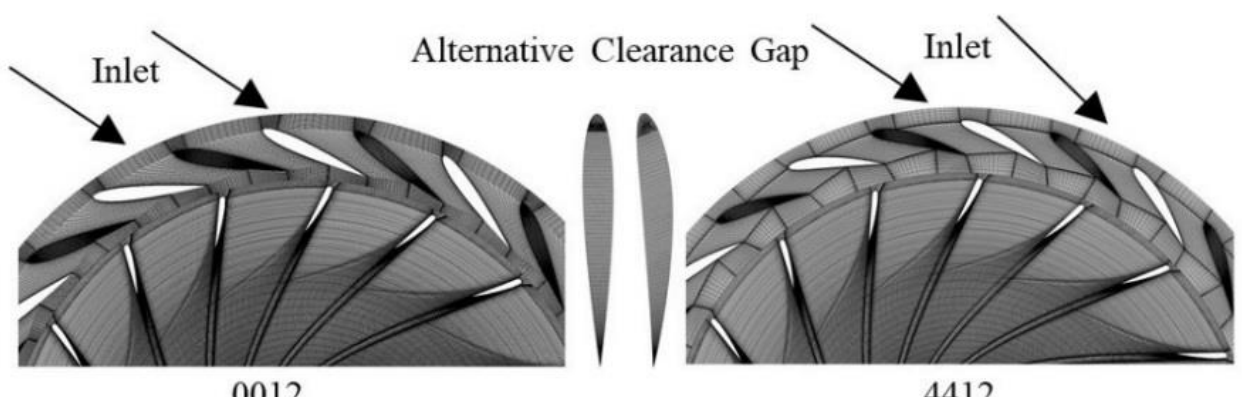

Fig. 4. Numerical model for alternative leakage flow.

$h=\left[\frac{1}{N} \sum_{i=1}^{N}\left(\Delta V_{i}\right)\right]^{1 / 3}$

ii) Let $h_{1}<h_{2}<h_{3}$ and $r_{21}=h_{2} / h_{1}, r_{32}=h_{3} / h_{2}$, the apparent order, was solved as in Eqs. 6,7 and 8 using fixed-point iteration method,

$$
\begin{aligned}
& p=\frac{1}{\ln \left(r_{21}\right)}|\ln | \varepsilon_{32} / \varepsilon_{21}|+q(p)| \\
& q(p)=\ln \left(\frac{r_{21}^{p}-s}{r_{32}^{p}-s}\right) \\
& s=1 . \operatorname{sign}\left(\varepsilon_{32} / \varepsilon_{21}\right)
\end{aligned}
$$

iii) The extrapolated values were calculated as,

$$
\phi_{e x t}^{21}=\left(r_{21}^{p} \phi_{1}-\phi_{2}\right) /\left(r_{21}^{p}-1\right)
$$

iv) Approximate and extrapolated relative error was calculated as,

$$
\begin{aligned}
& e_{a}^{21}=\left|\frac{\phi_{1}-\phi_{2}}{\phi_{1}}\right| \\
& e_{\text {ext }}^{21}=\left|\frac{\phi_{e x t}^{12}-\phi_{1}}{\phi_{\text {ext }}^{12}}\right| \\
& G C I_{\text {fine }}^{21}=\frac{1.25 e_{a}^{21}}{r_{21}^{p}-1}
\end{aligned}
$$

Three different mesh with the number of elements as shown in Table 1, were used to measure numerical uncertainty. A monitor point, Point 1 was introduced inside the runner domain to monitor pressure with three different mesh. Point 1 was located inside the rotating domain as shown in Fig. 5, so that the uncertainties during runner rotation could also be observed.

In this case efficiency of the turbine and pressure at Point 1 were considered parameters for measuring the uncertainty. Efficiency was measured using Euler turbine equation as the ratio of power output to the power input. Power output was calculated from the torque of the turbine and its rotational speed, whereby power input was obtained from the net head acting on the turbine. Uncertainty in the efficiency measurement from medium mesh to fine mesh was found to be $0.0033 \%$. This gives good agreement in measuring the efficiency with any of fine mesh or medium mesh. However, the coarse mesh scheme shows a very low efficiency of the turbine. Thus, the coarse mesh was not used for further numerical study. Measurement of uncertainty in the pressure gives $0.198 \%$ from medium mesh size to fine mesh.

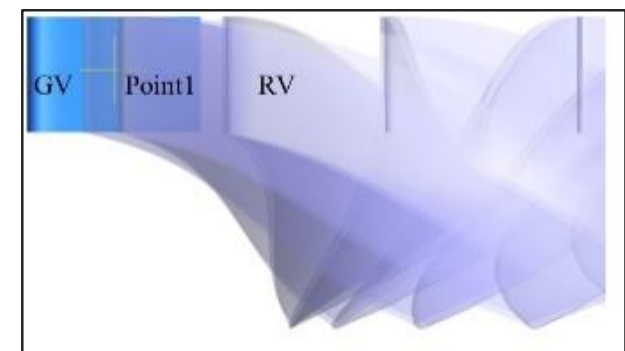

Fig. 5. Point 1 inside runner domain.

In Figs. 6a-b velocity along GV profile is shown from the leading edge to trailing and back to the leading edge, thus covering PS and SS of GV profile with 43 points in the profile. First half in each figure shows the uncertainty in velocity measurement in PS and SS for second half separated by a solid line. It is seen that length of the uncertainty band is less in leading edge area than that of trailing edge. This may be due to wake flow downstream the GV region and higher-pressure difference near the trailing region. This is further explained in the experimental validation of the numerical case (section 3.2).

\subsection{Selection of Clearance Gaps}

In the presented study $24 \mathrm{GVs}$ are present. The influence of clearance gaps at different periodic positions of $\mathrm{GV}$ is studied in this section. For runner rotation of 1000 revmin $^{-1}$, blade passing frequency ( $\mathrm{fb}$ ) for the turbine is $400 \mathrm{~Hz}$. In case of GV without clearance gap $\mathrm{f}_{\mathrm{b}}$ occurs exactly at $400 \mathrm{~Hz}$ and consequently to $2 \mathrm{fb}_{\mathrm{b}}, 3 \mathrm{fb}_{\mathrm{b}} \ldots$, corresponding to $800 \mathrm{~Hz}$, $1200 \mathrm{~Hz}$ and so on as shown in Fig. 7a. The peak pressure pulsation is due to the rotor-stator interaction.

In the second case, when a single clearance gap is selected in a single guide vane with all other GV's without it, the effect of clearance gap is observed at 
(a)

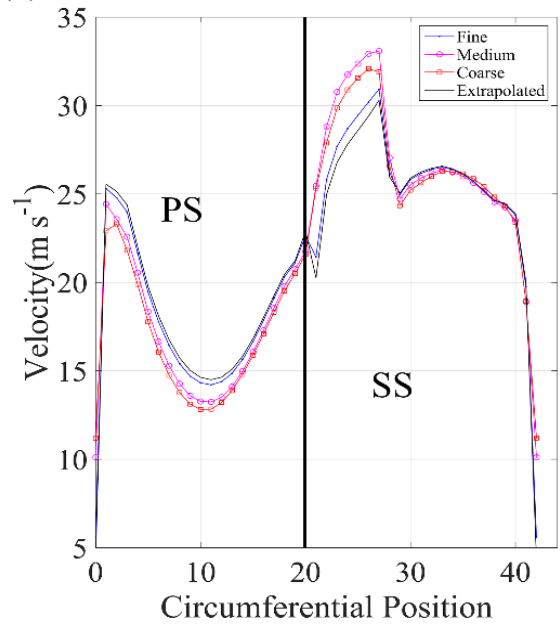

(b)

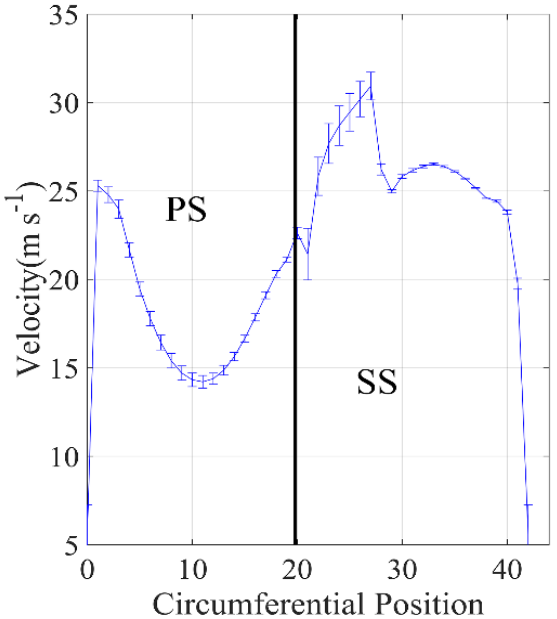

Fig. 6. Numerical validation of reference case: (a) Extrapolated results, (b) Uncertainty measurement.

(a)

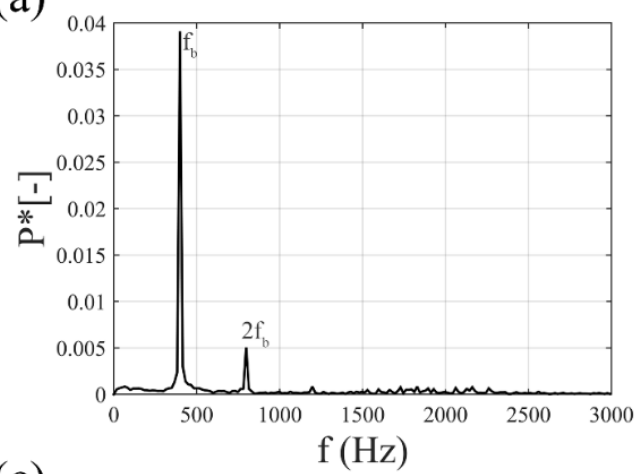

(c)

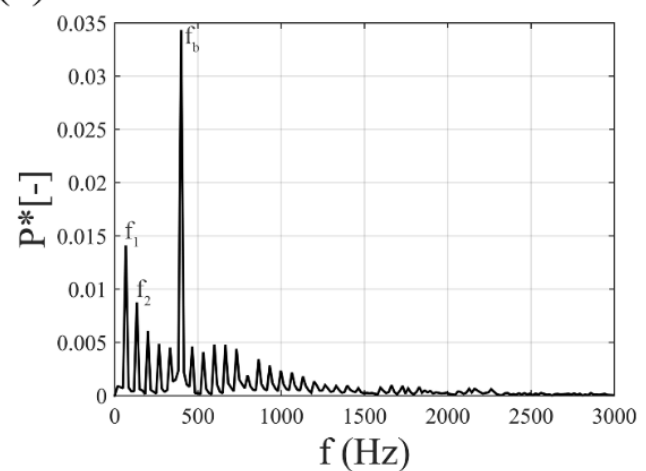

(b)

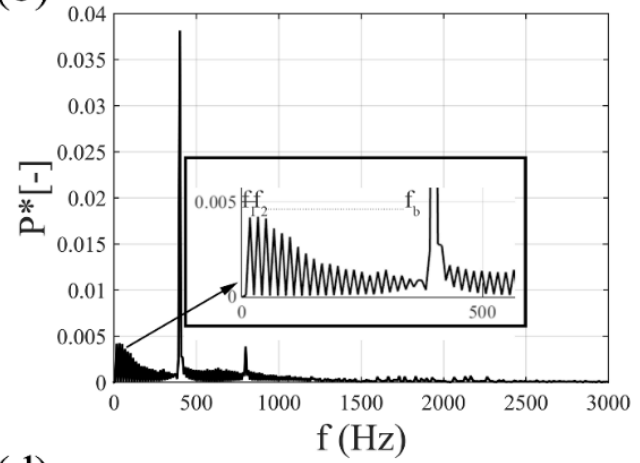

(d)

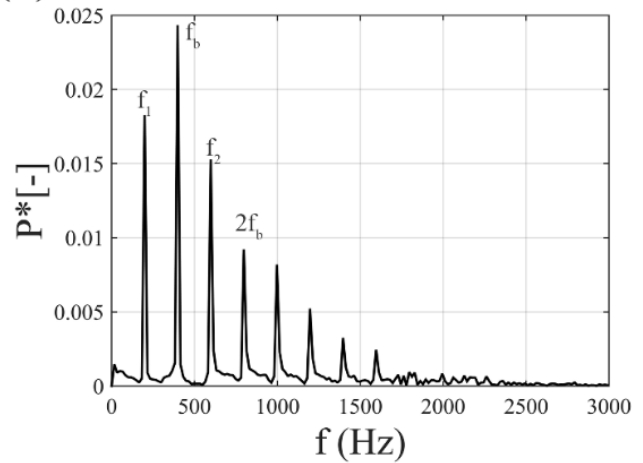

Fig. 7. FFT of pressure pulsation inside runner (a) Without clearance gap, (b) Single clearance gap, (c) Four clearance gap periodically and (d) With alternative clearance gap.

frequency corresponding to $\mathrm{f}_{\mathrm{b}} / 24 \mathrm{~Hz}$. Thus, the first harmonics of pressure pulsation occurs at $16.67 \mathrm{~Hz}$. Consequently, other successive harmonics $\mathrm{f}_{2}, \mathrm{f}_{3} \ldots$. occurs at $2 * 16.67=33.33 \mathrm{~Hz}, 3 * 16.67=50 \mathrm{~Hz}$ and so on as shown in Fig.7b. These occurrences of peak pressure pulsations before $\mathrm{f}_{\mathrm{b}}$ are due to the presence of a clearance gap at single GV alone. Furthermore, 4 clearance gaps were presented in 4 consecutive $\mathrm{GVs}$ at a $90^{\circ}$ span. As discussed above, in this case first harmonics should occur at $4 * \mathrm{fb} / 24 \mathrm{~Hz}$ i.e. 66.67 Hz. Consequently, other successive harmonics occur at $2 * \mathrm{f}_{1}, 3 * \mathrm{f}_{1} \ldots$ corresponding to $133.333 \mathrm{~Hz}, 200$
Hz.... and so, on as shown in Fig. 7c. In this case as well, these peak pressure pulsations are solely due to the presence of clearance gap in GV.

Finally, clearance gaps are placed alternatively in 24 GVs. Thus, in 24 GVs there are 12 clearance gaps, each gap placed at 30 degrees of periodic positions. As discussed above, in this case the effect of leakage flow can be analytically observed at $12 * \mathrm{f}_{\mathrm{b}} / 24 \mathrm{~Hz}$ i.e. $200 \mathrm{~Hz}$. Thus, at $200 \mathrm{~Hz}$ effect of the clearance gap can be solely observed. Other successive harmonics corresponding to the effect of leakage flow occurs at 


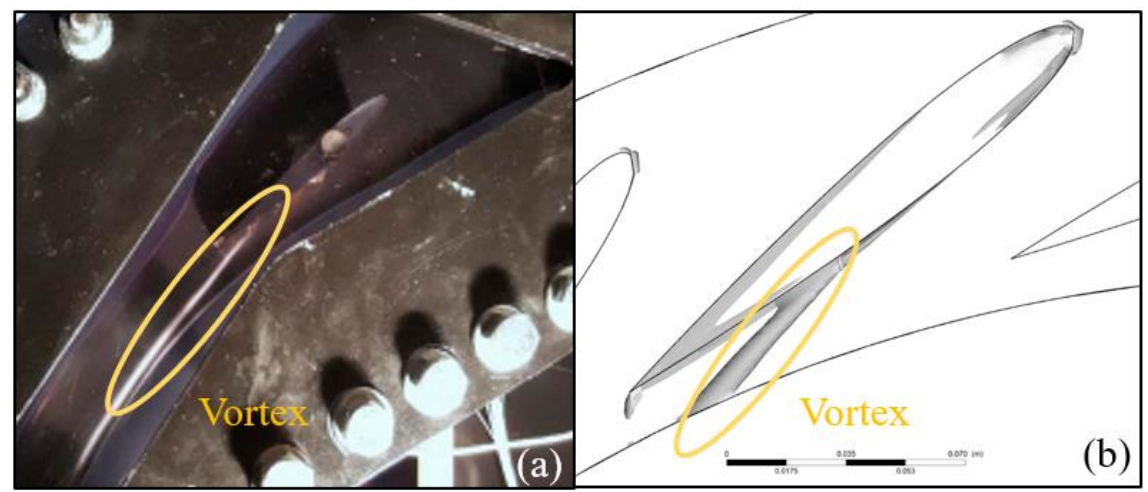

Fig. 8. Experimental validation: (a) Flow field GV-PIV Experiment, (b) CFD results (Chitrakar, Dahlhaug, and Neopane, 2018).

Table 1 Discretization error in numerical case

\begin{tabular}{|c|c|c|c|c|c|c|}
\hline \multirow[b]{2}{*}{ Grid Type } & \multicolumn{2}{|c|}{ Number of Elements } & \multirow{2}{*}{$\begin{array}{l}\text { Grid Refinement } \\
\text { Factor }(r)\end{array}$} & \multicolumn{2}{|c|}{ Measurement Parameter $(\phi)$} & \multirow{2}{*}{$\begin{array}{c}\text { Grid } \\
\text { Convergence } \\
\text { Index (GCI) }\end{array}$} \\
\hline & RV & GV & & Efficiency $\left(\phi_{1}\right)$ & $\begin{array}{c}\text { Pressure at } \\
\text { point } 1(\mathrm{kPa}) \\
\left(\phi_{2}\right)\end{array}$ & \\
\hline Coarse & 317016 & 144144 & \multirow{3}{*}{$\begin{array}{l}r^{21}=1.521 \\
r^{32}=1.443\end{array}$} & 76.817 & 1447.337 & \multirow{3}{*}{$\begin{array}{l}\phi_{1}=0.003 \% \\
\phi_{2}=0.198 \%\end{array}$} \\
\hline Medium & 1034319 & 346028 & & 96.642 & 1271.812 & \\
\hline Fine & 3614093 & 1233216 & & 96.949 & 1250.591 & \\
\hline
\end{tabular}

$400 \mathrm{~Hz}, 600 \mathrm{~Hz}, 800 \mathrm{~Hz}$ and so on. In this case, since $400 \mathrm{~Hz}$ is the effect of RSI, its effect is observed at $\mathrm{fb}, 2 * \mathrm{fb}, 3 * \mathrm{fb}$, corresponding to $400 \mathrm{~Hz}, 800 \mathrm{~Hz}, 1200$ $\mathrm{Hz}$ and so on. The effect of the clearance gap observed predominantly at $200 \mathrm{~Hz}$ can be observed at $200 \mathrm{~Hz}, 400 \mathrm{~Hz}, 600 \mathrm{~Hz}$ and so on as shown in Fig.7. d. Thus, using an alternative clearance gap effect of clearance gaps can be observed before RSI making an alternative clearance gap method suitable for predicting effects of leakage flow.

\subsection{Validation with the Experimental Results}

The numerical solution obtained for the case was validated with experimental results from one GV cascade rig consisting of a prototype GV of Jhimruk HPP. CFD of the turbine was done with runner rotating case. In Fig. 8, the comparison of the vortex from the clearance gap of GV from experiment and CFD is given. The vortex flow is similar to that of CFD. In the figure the flow vortex originating from the clearance gap of GV travels from GV inlet to outlet and leaves GV trailing edge. Similar flow behavior is observed in CFD results of the current case. Due to the small distance between GV and runner, the vortex tends to travel from the trailing edge and hit inlet of the runner. This gives good agreement between the current numerical case and experiment. Thus, the validated numerical model was further used with different operating conditions and different sizes of the clearance gap for analysis.

\section{Results AND Discussions}

\subsection{Leakage flow From GV}

Flow travelling from the leading edge of GV towards the trailing edge experiences significant pressure difference. Similarly, along the trailing edge of the $\mathrm{GV}$, wakes are build-up. The pressure difference along GV span, wakes travelling beneath trailing edge and leakage flow from clearance gap affects the performance of runner. Flow behavior, when fluid enters GV profile is shown in the Fig. 9. Cylindrical planes of 15 degrees' circular sector were created in GV profile. Thus, there were 4 different planes from leading edge to trailing edge. The plot of normalized total pressure contour (CTP) was observed in the case of NACA 0012, NACA 2412 and NACA 4412 hydrofoils. The normalized pressure is the ratio of total pressure to the average total pressure at the inlet (Chitrakar, Thapa, Dahlhaug, \& Neopane, 2017). This gives loss of pressure energy of fluid while travelling from leading edge to trailing edge, such that value below 1 corresponds to losses. Inside the GV profile, NACA 0012 has the higher effect of leakage flow towards trailing edge than others.

Leakage flow builds up gradually from the inlet of GV to outlet. The magnitude of leakage flow is increased while flow travels from the asymmetrical profile. As seen in Fig.9, inside GV domain, the NACA0012 GV profile has a region near the 


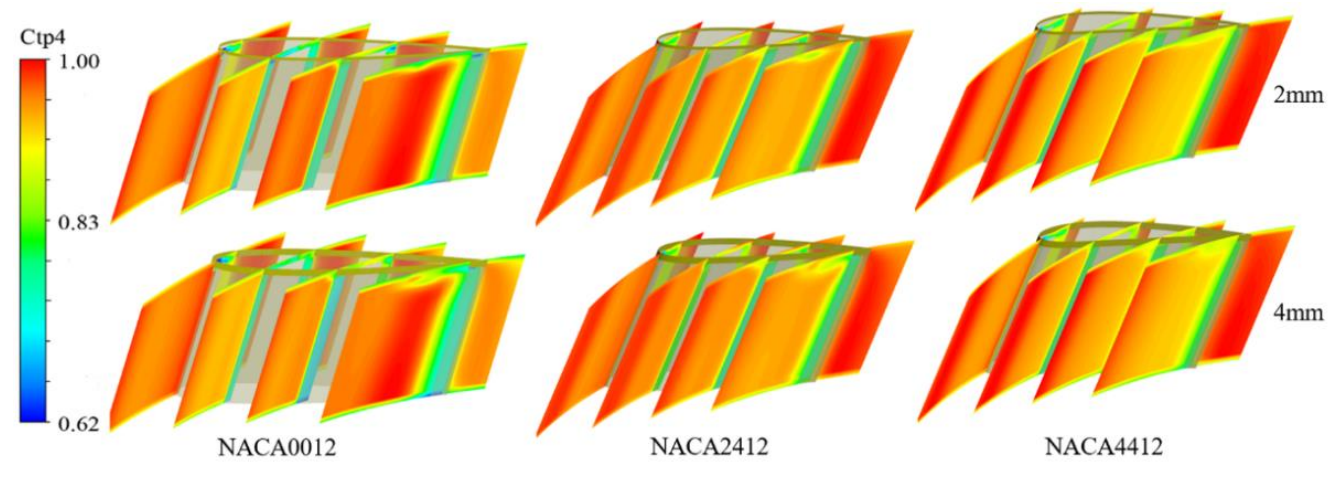

Fig. 9. Development of leakage flow inside GV.

clearance gap where vortex magnitude gradually increases with increasing thickness. In the case of asymmetrical 2412 and $4412 \mathrm{GV}$ profiles, the vortices tend to dissipate. This is due to the build-up of cross leakage near the leading edge of GV in case of the asymmetrical profile, which during its travel tend to dissipate.

However, the positive consequence of a faster a build-up of leakage flow in NACA 4412 can be build-up of vortices before runner inlet. These vortices seem to hit the adjacent GV surface instead of the runner inlet. However, due to the larger distance between adjacent GVs, the vortices supposed to hit adjacent GV are deflected away by free-flowing fluid entering GV.

Though the effect of leakage flow in GV seems higher in case of asymmetrical GV profile than symmetrical one, flow beneath GV trailing edge shows the opposite trend while moving towards runner inlet. Figure 10 shows the development of fluid flow from GV trailing edge towards runner inlet in stationary GV domain. The main flow flowing from GV surface experiences disturbances from secondary flow due to cross leakage and wakes from trailing edge. The clearance gap induces negative effects on flow behavior. Three different GV profiles are compared with the same range of CTP. In the case of any GV profile it is seen that the maximum loss in pressure energy occurs in near clearance gap region. However, least in case of asymmetrical NACA $4412 \mathrm{GV}$ profile, since leakage travels to the adjacent $\mathrm{GV}$ due to higher pressure difference at the leading edge instead of moving forward towards runner inlet. The minimum CTP observed near clearance gap represents vortex filament leaving GV. The strength of vortex increases while it travels from GV trailing edge and decreases in case of NACA $0012 \mathrm{GV}$ profile for $2 \mathrm{~mm}$ clearance gap. Similarly, same trend of vortex travel is observed in case while travelling in $4 \mathrm{~mm}$ clearance gap. In case of NACA 2412 GV profile, low-intensity vortex grows up while it travels from $\mathrm{GV}$ trailing edge for all clearance gaps. However, the vortex seems to dissociate gradually while it travels from NACA 4412 GV profile with all clearance gap. The flow field depicts similar findings in the past experiment with single GV test rig in the case of NACA 0012 hydrofoil (Thapa, Dahlhaug, and Thapa, 2017 a, b).
Flow leaving the GV domain enters the rotating domain of runner. Thus, there occur significant flow disturbances mainly due to the secondary flow from GV. Figure 11 shows CTP inside the rotating frame of reference after runner revolution. It shows the effect of vortex travelling from GV towards runner domain. Since the intensity of vortex travelling inside runner had higher differences with three different GV profiles, these are plotted against their own respective local magnitude of CTP. The lowest value of CTP, corresponding to highest losses occurs in NACA 0012 hydrofoil with $2 \mathrm{~mm}$ thickness. In the case of NACA 2412 hydrofoil, though with the lesser magnitude of CTP at 0.80 , a distinct region for vortex occurring can be observed with $2 \mathrm{~mm}$ and $4 \mathrm{~mm}$ clearance gap. Same as in the stationary domain, the vortex has dissociated in case of NACA 4412 hydrofoil. This is due to the vortex travelling to the adjacent GV surface instead of the runner inlet in the case of NACA 4412. Thus, this increase in vortex filament in case of NACA $0012 \mathrm{GV}$ profile induces the pressure pulsations and vibrations in the turbine, more adversely abrasive and erosive wear of runner.

\subsection{Pressure Pulsation Inside Runner}

A total of 5 points was located inside the rotating runner with $50 \%$ of geometric progression along the length of the span as shown in Fig. 12. These points were able to experience a change in the monitored value of total pressure due to any leakage flow or RSI. Thus, the points were monitored at each degree runner rotation after converged solution.

The numerical model of NACA 2412 and NACA 4412 hydrofoil has an angular shift of 15 degrees with reference NACA 0012 hydrofoil. So, the peak pressure can be observed in every 15 degrees alternatively with the reference case. This makes it capable to distinguish the peak pressure during each degree runner rotation for both the cases as shown in Fig. 13. The pressure pulsation was obtained by subtracting mean pressure $(\bar{P})$ with instantaneous pressure $(\mathrm{P})$ and normalized with reference pressure (Trivedi, Cervantes, and Gandhi, 2016).

$$
p^{*}=\frac{P-\bar{P}}{(\rho \cdot E)_{B E P}}[-]
$$


S. Gautam et al. / JAFM, Vol. 13, No. 5, pp. 1407-1419, 2020.

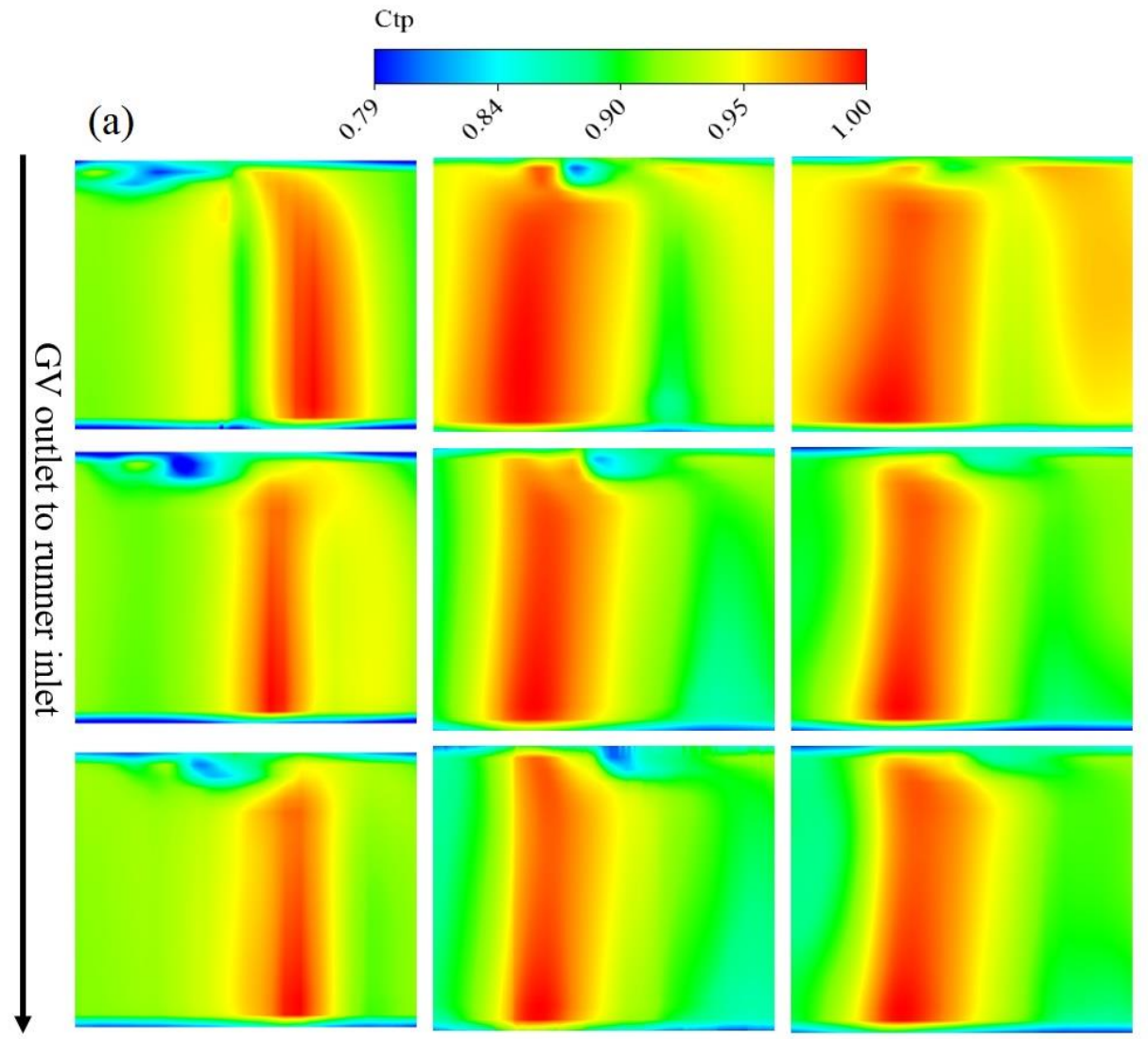

(b)

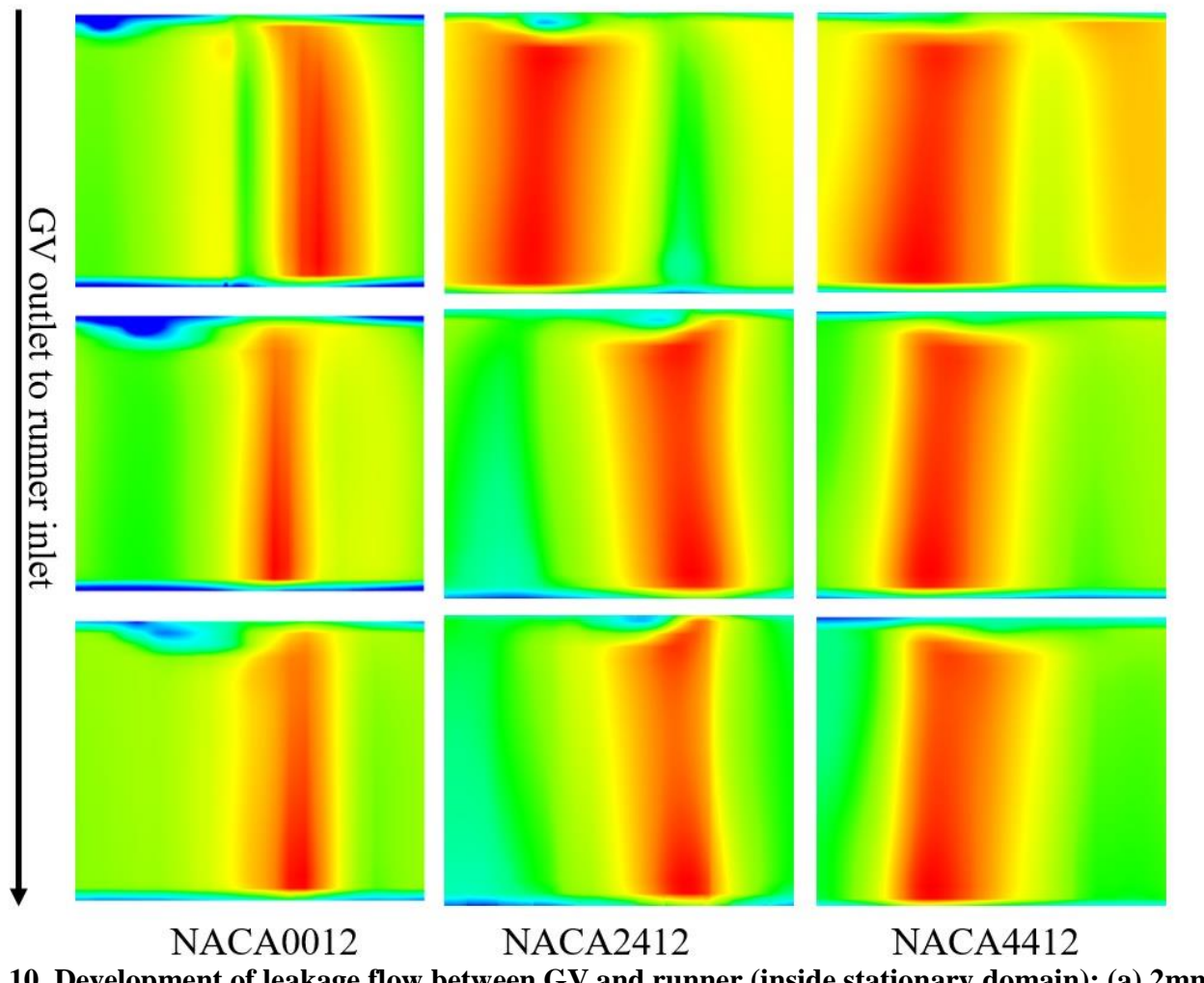

Fig. 10. Development of leakage flow between GV and runner (inside stationary domain): (a) $2 \mathrm{~mm}$ Thickness, (b) 4 mm Thickness. 
S. Gautam et al. / JAFM, Vol. 13, No. 5, pp. 1407-1419, 2020.

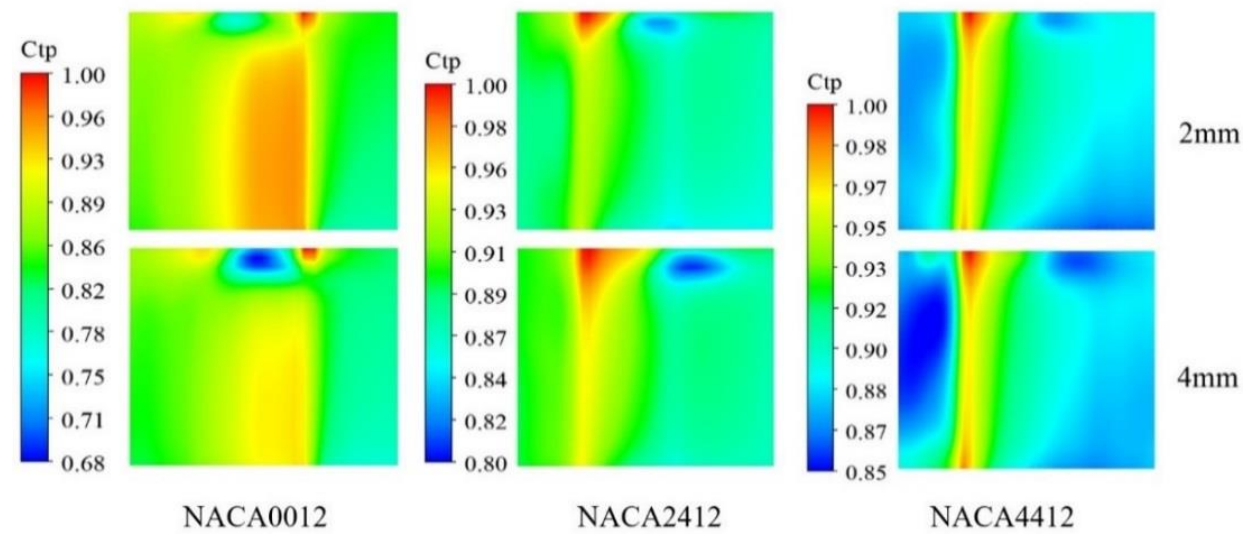

Fig. 11. Normalized total pressure contours at runner inlet (inside rotating domain).

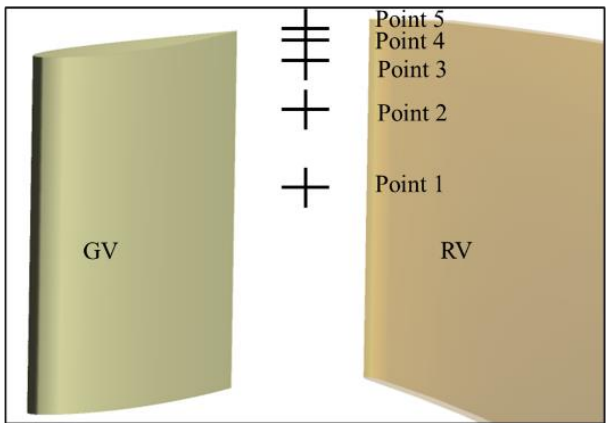

Fig. 12. Points between GV and RV inside the rotating domain.

(a)

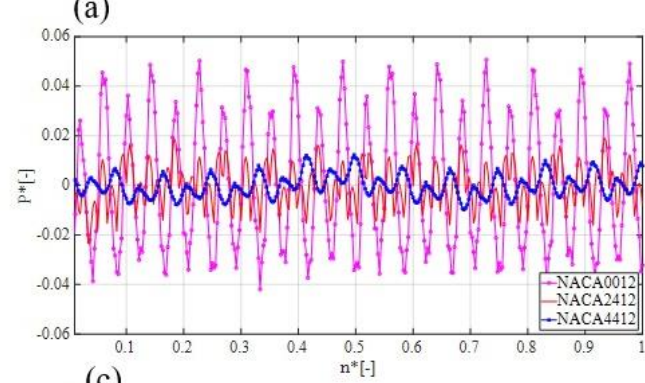

(c)
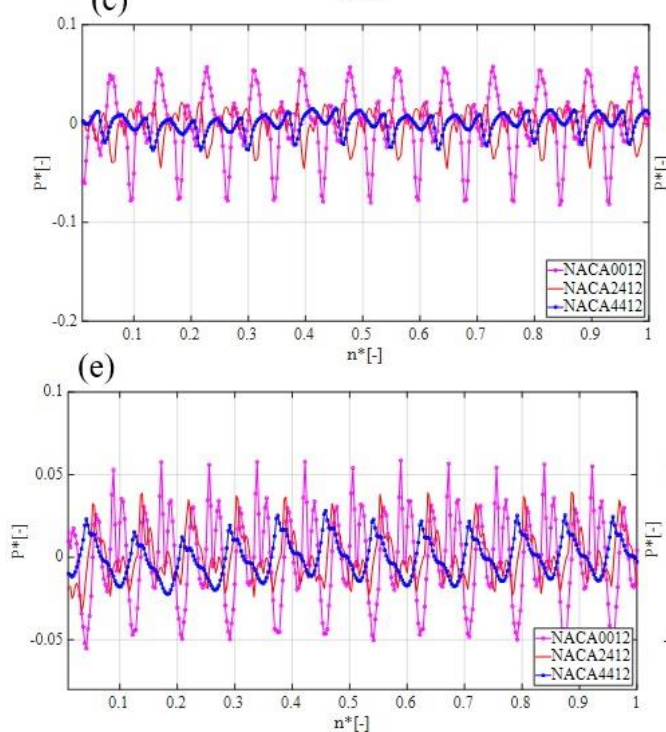

(b)

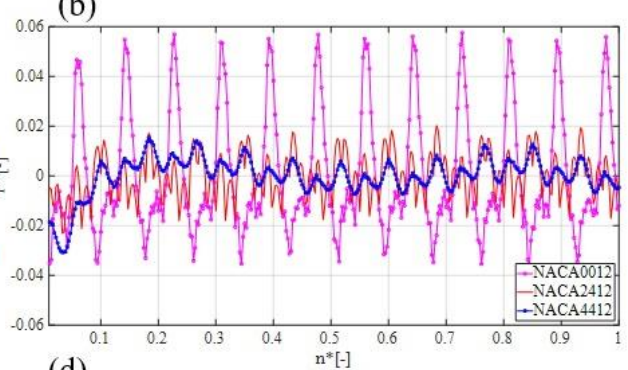

(d)
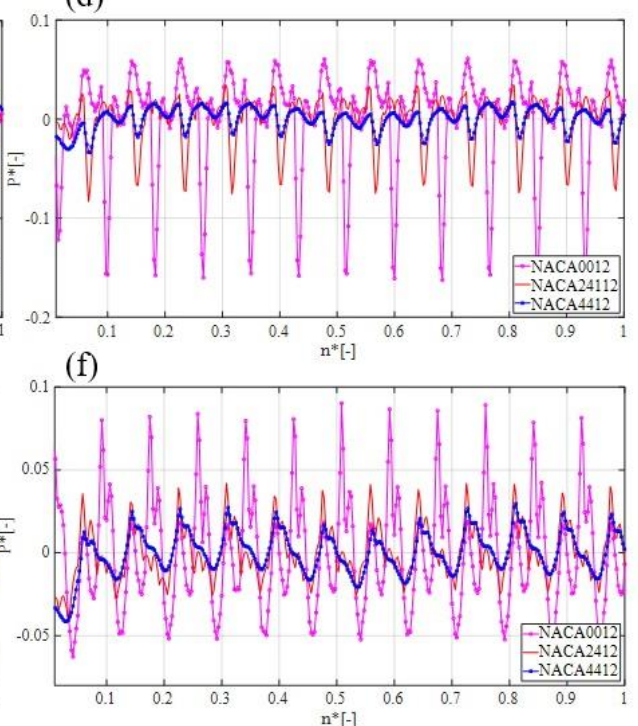

Fig. 13. Pressure pulsation at different points inside runner: (a-b) Point 5, (c-d) Point 3 and (e-f) Point 1. 
The instantaneous runner rotation $(\mathrm{n} *)$ was normalized by total runner rotation in degrees. It is seen that NACA 4412 has lower peak pressure pulsation value than that of NACA 2412 and NACA 4412 with both clearance gap sizes. Higher pressure fluctuation near clearance gap was previously studied by (Chitrakar, Thapa, Dahlhaug, and Neopane, 2017; Chitrakar, Dahlhaug, and Neopane, 2018). Point 5, Point 3 and Point 1 were taken for the comparison of the effects of leakage flow. The pressure fluctuation at that point is affected by both RSI and vortex originating from the clearance gap which can be seen by two peaks at each blade passing frequency on Point 5 and Point 3. Point 1 does not contain additional peak pressure which shows that the point at mid-span of GV is least affected by leakage flow Figure 14 shows the significance of using an alternative clearance gap for comparison

Table 2 Percentage reduction in peak pressure pulsation with reference to NACA 0012 GV profile

Case I: NACA 2412 GV Profile

\begin{tabular}{|c|c|c|c|c|c|}
\hline Case & Point1 & Point2 & Point3 & Point4 & Point5 \\
\hline No Leakage & 78.62 & 78.66 & 78.96 & 79.91 & 80.23 \\
\hline 2mm Leakage & 62.20 & 55.41 & 57.92 & 54.40 & 18.93 \\
\hline 4mm Leakage & 80.66 & 3.78 & 65.30 & 31.31 & 37.05 \\
\hline
\end{tabular}

Case II: NACA 4412 GV Profile

\begin{tabular}{|c|c|c|c|c|c|}
\hline No Leakage & 87.26 & 87.63 & 87.41 & 87.76 & 88.28 \\
\hline 2mm Leakage & 76.59 & 68.78 & 80.33 & 84.61 & 76.62 \\
\hline 4mm Leakage & 90.95 & 66.26 & 89.34 & 44.09 & 47.03 \\
\hline
\end{tabular}

of effects of leakage flow. In Fig. 14a containing no leakage, Fourier transformed peak pressure is observed at $400 \mathrm{~Hz}$ sampling frequency which is the blade passing frequency for the current numerical case. However, in Fig. 14b-c with $2 \mathrm{~mm}$ and $4 \mathrm{~mm}$ leakage, the peak pressure pulsation is observed at 200 $\mathrm{Hz}$. This peak pressure pulsation obtained at $200 \mathrm{~Hz}$ is due to leakage flow alone and peak observed at 400 $\mathrm{Hz}$ is due to RSI. It is seen that the effect of leakage flow is higher with higher thickness of the clearance gap. In case of NACA 0012 GV at Point 3, amplitude of pressure pulsation is higher than in other points at $200 \mathrm{~Hz}$. This agrees with past study in a single GV test rig (Chitrakar, Thapa, Dahlhaug, \& Neopane, 2017), where the shifting of the vortex towards mid-span while traveling downstream of $\mathrm{GV}$ was observed. Shifting of the vortex in the case of NACA 2412 hydrofoil was observed at point 3 and point 5 . Since, the intensity of vortex travelling from NACA 2412 hydrofoil was lower, while travelling it tends to hit the adjacent surface of the runner inlet whereby gets dissipated from the main flow again near point 3 . Thus, a higher amplitude of pressure oscillation can be observed at point 5 than at blade passing frequency $\left(\mathrm{f}_{\mathrm{b}}\right)$. In the case of NACA 4412, higher pressure pulsation was observed at point 5 , near the clearance gap which shows that the vortex shift has not occurred due to leakage flow. This signifies that the intensity of vortex filament leaving the clearance gap is least in the case of NACA 4412 hydrofoil.

Table 2 shows a comparison of the pressure pulsation with different sizes of clearance gaps. In no leakage condition where pressure pulsation occurs only due to RSI, NACA $4412 \mathrm{GV}$ profile has the least effect at all the points. A comparison of the peak pressure pulsation for no leakage condition was made at $f_{b}$ of $400 \mathrm{~Hz}$. In other cases, containing leakage, pressure pulsation was measured at first harmonics of pressure signal i.e. $200 \mathrm{~Hz}$. In any cases, the change in peak pressure pulsation with reference to NACA 0012 hydrofoil was negative, lowest value for NACA 4412 hydrofoil. This agrees with the past study that asymmetric $\mathrm{GV}$ profile has the least effect on pressure pulsation (Chitrakar, Thapa, Dahlhaug, and Neopane, 2017; Chitrakar, Neopane, and Dahlhaug, 2017; Koirala, Neopane, Shrestha, Zhu, and Thapa, 2017; Chitrakar, Dahlhaug, and Neopane, 2018). Since all these studies were conducted with the clearance gap in all GVs, the distinguished effects of only leakage flow were not studied. However, with alternative clearance gap approach effects of only leakage flow were observed and compared.

The vortex of leakage flow carried down by the main flow enters runner inlet. These vortices tend to deviate the design angle of main flow. Figure 15 shows isosurface swirling strength constituting of velocity travelling towards runner from alternative clearance gaps. It represents the imaginary part of complex eigenvalues of velocity gradient tensor. The positive value of discriminant of velocity gradient tensor for complex eigenvalues gives positive swirling strength, indicating the existence of swirling motion around local centers. The magnitude of swirling strength of vortices increases with the increase in clearance gap at $1000 \mathrm{~Hz}$. NACA 4412 has the least value of velocity travelling with the vortices. This least velocity vortex hits runner inlet which reduces the effects of erosion using an asymmetrical profile. NACA $2412 \mathrm{GV}$ profile has marginal strength of vortex travelling to the runner inlet. 


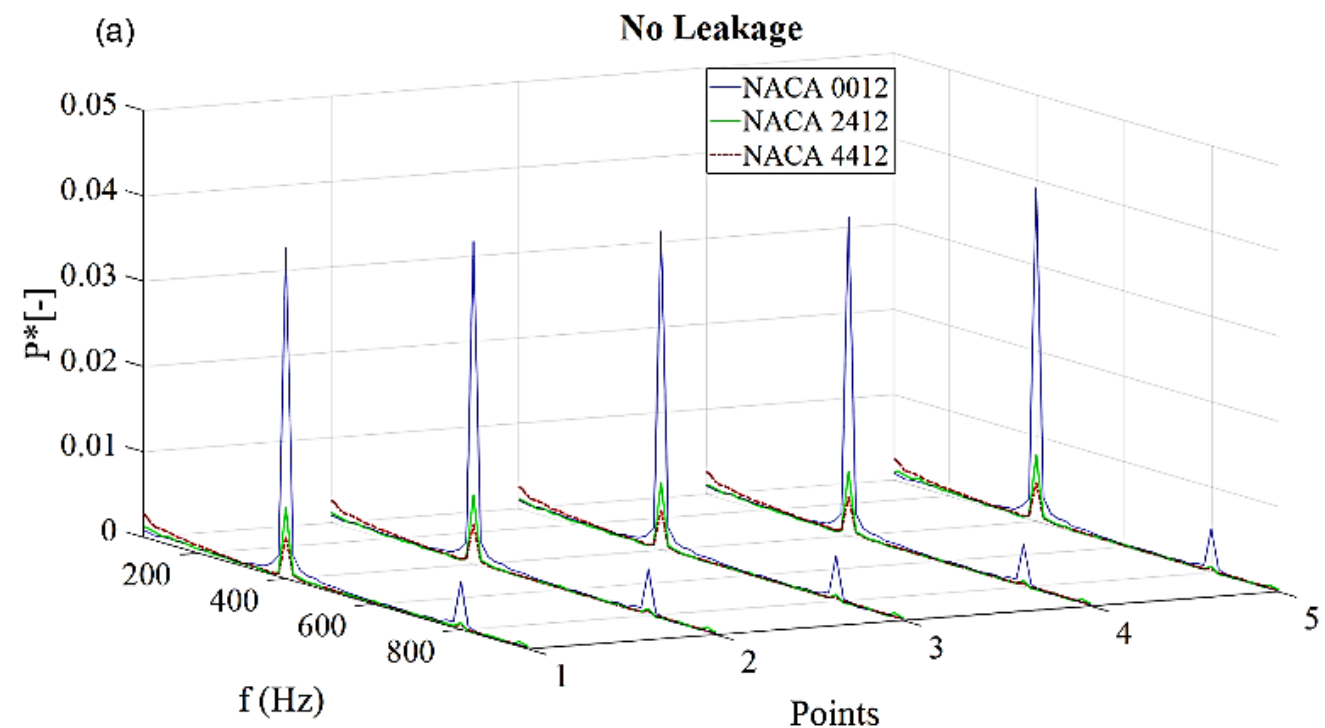

(b)

2mm Leakage

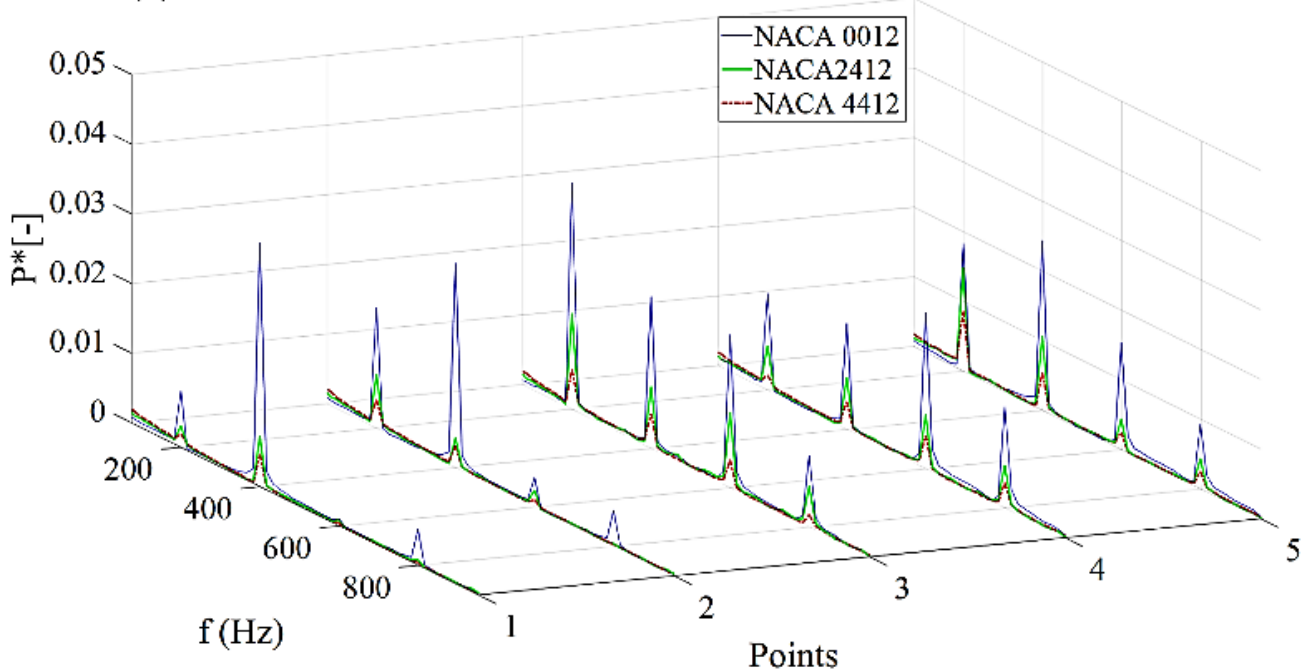

(c) $4 \mathrm{~mm}$ Leakage

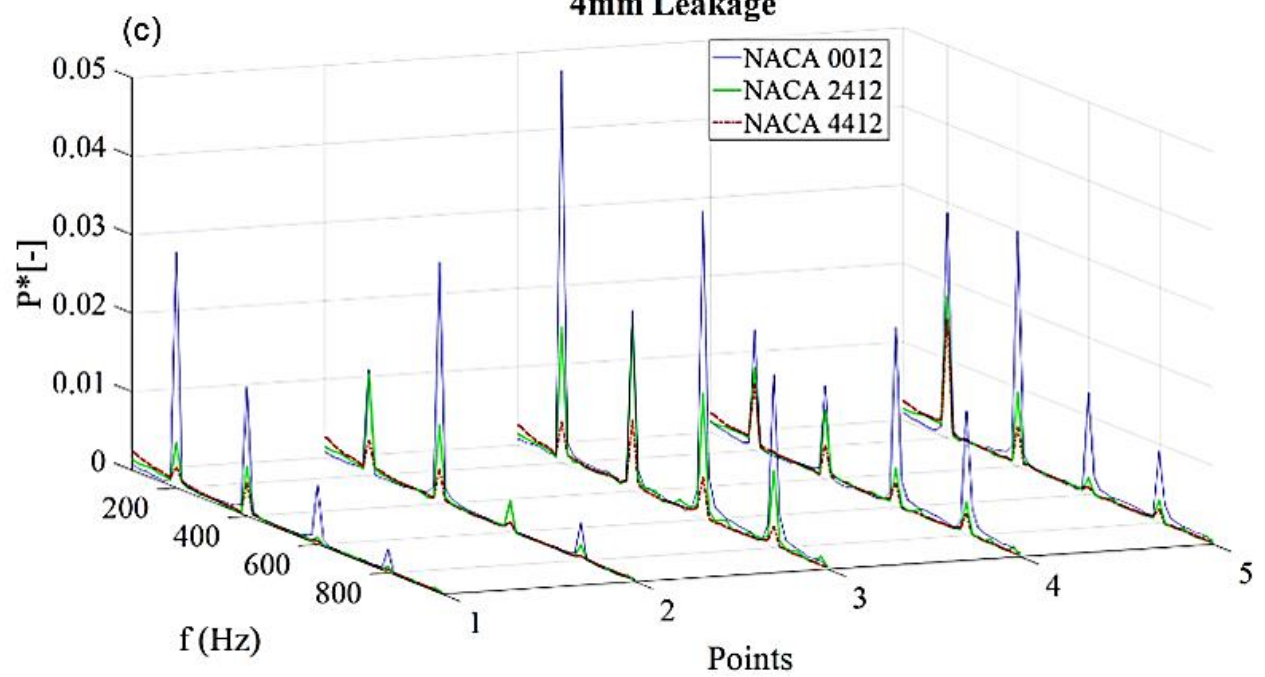

Fig. 14. FFT of the pressure pulsations inside runner domain: (a) No leakage (b) $2 \mathrm{~mm}$ leakage, (c) 4 mm leakage. 


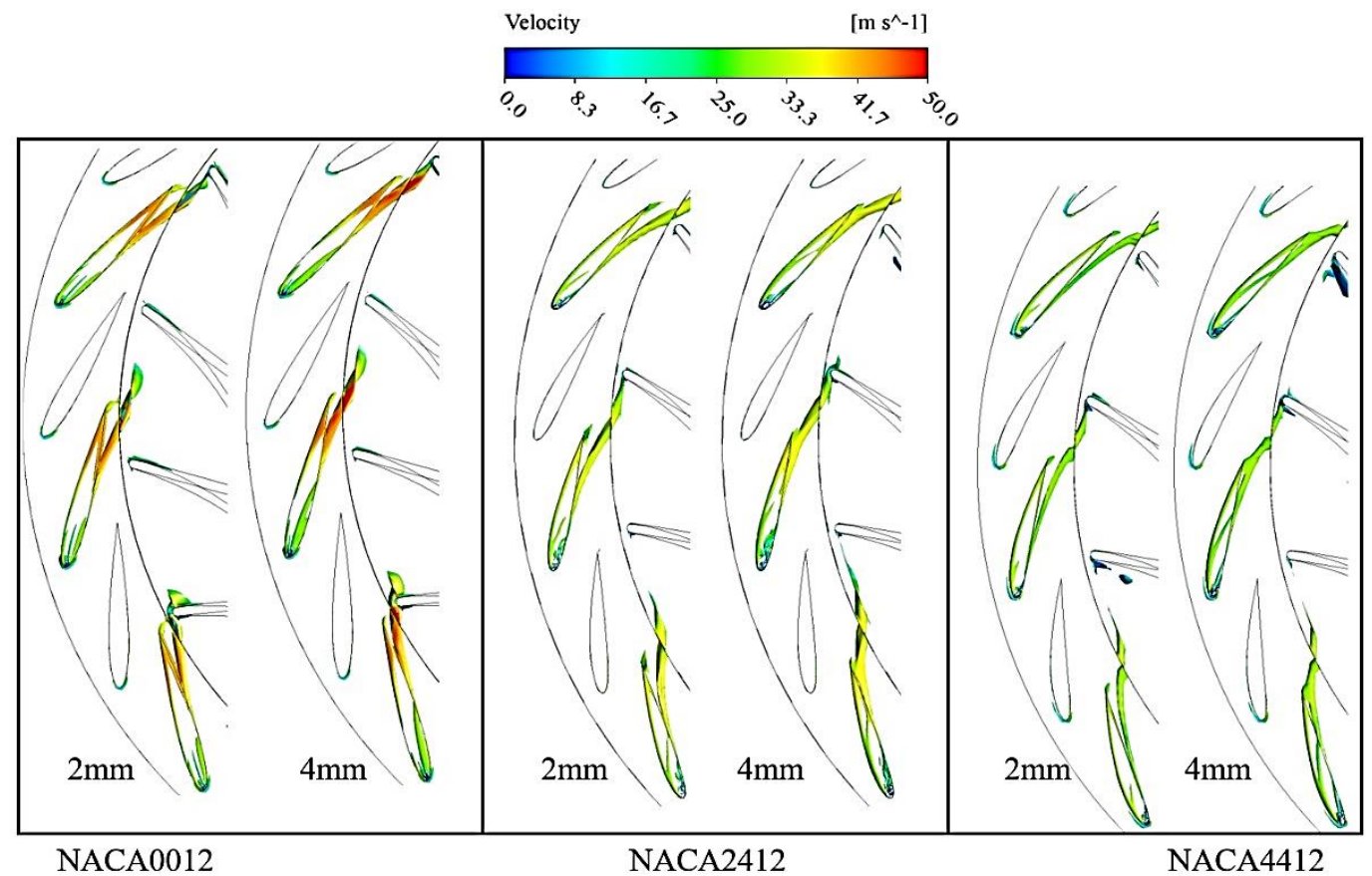

Fig. 15. Vortex core region at $1000 \mathrm{~Hz}$.

\section{CONClusion}

A numerical investigation of leakage flow using an alternative clearance gap was studied using asymmetrical and symmetrical GV profiles. Clearance gaps with $2 \mathrm{~mm}$ and $4 \mathrm{~mm}$ sizes were introduced inside the GV domain. Flow leaving the clearance gap was monitored with steady-state and transient state numerical solution. Thus, the solution for the numerical case was validated with the grid scaling test and experiment on the same case.

Vortices leaving the GV in NACA 4412 travels towards the GV surface whereby these vortices are deflected by the primary flow entering the GV domain. In the case of NACA 0012, it travels towards the runner inlet thus hitting inlet of the runner at very high velocity. NACA $2412 \mathrm{GV}$ profile has the marginal intensity of vortex travelling into runner inlet. The vortices travelling from GV trailing edge to adjacent GV surface instead of the inlet of the runner have very least contribution for wear in the surface. The results may impart abrasive wear in GV surface in case of NACA 4412 profile. The numerical pressure time signals were analyzed with FFT. The effect of leakage flow on pressure pulsation at runner was separated from RSI using alternative clearance gap method. These differentiated pressure amplitudes from RSI was compared for all GV profiles at different leakage scheme. It was studied that the amplitude of pressure pulsation at the inlet of runner reduced up to $62.20 \%$ using NACA 2412 and up to $84.61 \%$ using NACA 4412 compared to NACA 0012 hydrofoil with $2 \mathrm{~mm}$ clearance gap. Similarly for $4 \mathrm{~mm}$ clearance gap, amplitude of pressure pulsation reduced up to
$80.66 \%$ and $90.95 \%$ using NACA 2412 and NACA 4412 hydrofoil respectively.

Overall, the frequency spectrum at the same operating condition of the turbine showed the lesser amplitude of pressure pulsation in case of asymmetrical GV profile than for symmetrical one with any thickness of clearance gap. Leakage flow through asymmetrical GV profile has the least contribution in pressure pulsation than that for symmetrical one.

\section{ACKNOWLEDGEMENTS}

Authors would like to thank Turbine Testing Lab, Kathmandu University and Department of Energy and Power Engineering, Tsinghua University for research support. The research is supported by EnergizeNepal Project at TTL, "Establishment of centre for design, operation and maintenance of mechanical equipment for hydropower plants in Himalayan region at Kathmandu University". Authors would like to thank Mr. Ram Lama, PhD Research Fellow at Turbine Testing Lab, for his continuous support.

\section{REFERENCES}

Acharya, N., C. Trivedi, N. M. Wahl, S. Gautam, S. Chitrakar and O. G. Dahlhaug (2019). "Numerical study of sediment erosion in guide vanes of a high head Francis turbine", IOP Conf. Series: Journal of Physics: Conf. Series, No. 1266:12004.

Brekke, H. (1988). The influence from guide vane clearance gap on efficiency and scale effect for 
Francis turbines, IAHR International Symposium on Hydraulic Machinery and System,Section on hydraulic machinery equipment and cavitation, Trondheim, Norway.

Celik, I. B., U. Ghia, P. J. Roache, C. J. Freitas, H. Coleman and P. E. Raad (2008). Procedure for estimation and reporting of uncertainty due to discretization in CFD applications, Journal of Fluids Engineering 130(7), 078001.

Chitrakar, S., B. S. Thapa, O. G. Dahlhaug and H. P. Neopane (2016). Velocity and pressure measurements in guide vane clearance gap of a low specific speed Francis turbine, 28th IAHR symposium on Hydraulic Machinery and Systems, Grenoble, France.

Chitrakar, S., B. S. Thapa, O. G. Dahlhaug and H. P. Neopane (2017). Numerical and experimental study of the leakage flow in guide vanes with different hydrofoils, Journal of Computational Design and Engineering 4(3), 218-230.

Chitrakar, S., H. P. Neopane and O. G. Dahlhaug (2016). Study of the simulataneous effects of secondary flow and sediment erosion in Francis turbines, Renewable Energy 97, 881-891.

Chitrakar, S., H. P. Neopane and O. G. Dahlhaug (2017). Particle image velocimetry investigation of the leakage flow through clearance gaps in cambered hydrofoils, Journal of Fluid Engineering 139 (9), 091201.

Chitrakar, S., O. G. Dahlhaug and H. P. Neopane (2018). Numerical investigation of the effect of leakage flow through erosion-induced clearance gaps of guide vanes on the performance of Francis turbines, Engineering Applications of Computational Fluid Mechanics 12(1), 662678.

Eide, S. (2004). Numerical analysis of the head cover deflection and the leakage flow in the guide vanes of high head Francis turbines, $\mathrm{PhD}$ Thesis, Trondheim, Norway.

Eide, S. and H. B. Brekke (2002). Analysis of the head covers deflection and the leakage flow in the guide vanes, IAHR International Symposium on Hydraulic Machinery and System. Laussane.

Gautam, S., H. P. Neopane, N. Acharya, S. Chitrakar, B. S. Thapa and B. Zhu (2020). Sediment erosion in low specific speed Francis turbines: A case study on effects and causes, Wear442-443(203152).

Gautam, S., R. Lama, S. Chitrakar, H. P. Neopane, B. S. Thapa and B. Zhu (2019). Methodology to Predict Effects of Leakage Flow from Guide Vanes of Francis Turbine, IOP Conf. Series: Journal of Physics: Conf. Series, No. 1266:12003.

IEC (1991). Field acceptance tests to determine the hydraulic performance of hydraulic turbines, storage pumps and pump-turbines, Standard, Geneva, Switzerland.

Koirala, R., B. Thapa, H. P. Neopane and B. Zhu (2016). A review of flow and sediment eroison in guide vanes of Francis turbines, Renewable and Sustainable Energy Reviews 75, 10541065.

Koirala, R., B. Thapa, H. P. Neopane, B. Zhu and B. Chhetry (2016). Sediment erosion in guide vanes of Francis turbine: A case study of Kaligandaki hydropower plant, Nepal, Wear 362-363, 53-60.

Koirala, R., B. Zhu and H. P. Neopane (2016). Effect of Guide Vane Clearance Gap on Francis Turbine Performance, Energies 9(4) 275.

Koirala, R., H. P. Neopane, O. Shrestha, B. Zhu and B. Thapa (2017). Selection of guide vane profile for erosion handling in Francis turbines, Renewable Energy 112, 328-336.

Lama, R., D. R. Dahal, S. Gautam, N. Acharya, H. P. Neopane and B. S. Thapa (2018). Numerical investigation on performance and sediment erosion of Francis runner with different guide vane profiles, IOP Conf. Series: Journal of Physics: Conf. Series, No. 1042.

Neopane, H. P., O. G. Dalhaug and M. J. Cervantes (2012). The effect of sediment characteristics for predicting erosion on Francis turbine blades, Hydropower and Dams19(1) 79-83.

Thapa, B. (2004). Sand erosion in hydraulic machinery, $\mathrm{PhD}$ Thesis, Trondheim: Norwegian University of Science and Technology.

Thapa, B. S., O. G. Dahlhaug and B. Thapa (2012). Current research in hydraulic turbines for handling sediments, Energy 47, 62-69.

Thapa, B. S., O. G. Dahlhaug and B. Thapa (2015). Sediment erosion in hydro turbines and its effects on the flow around guide vanes of Francis turbine, Renewable and Sustainable Energy Reviews 49, 1100-1113.

Thapa, B. S., O. G. Dahlhaug and B. Thapa (2017a), Effects of sediment erosion in guide vanes of Francis turbine, Wear 390-391, 104-112.

Thapa, B. S., O. G. Dahlhaug and B. Thapa (2017b). Sediment erosion induced leakage flow from guide vane clearance gap in a low specific speed Francis turbine. Renewable Energy 107, 253261.

Thapa, B. S., O. G. Dahlhaug and B. Thapa (2018). Flow measurements around guide vanes of Francis turbine: A PIV approach, Renewable Energy 126, 177-188.

Trivedi, C., M. J. Cervantes and B. Gandhi (2016). Investigation of a high head Francis turbine at runaway operating conditions. Energies 9(3), 149. 